\title{
Quantifying uncertainty in the impacts of climate change on river discharge in sub-catchments of the Yangtze and Yellow River Basins, China
}

\author{
H. Xu ${ }^{1}$, R. G. Taylor ${ }^{2}$, and Y. $\mathrm{Xu}^{3}$ \\ ${ }^{1}$ National Climate Center, Laboratory for Climate Studies of China Meteorological Administration, Beijing, 100081, China \\ ${ }^{2}$ Department of Geography, University College London, Gower Street, London, WC1E 6BT, UK \\ ${ }^{3}$ State Key Laboratory of Urban and Regional Ecology, Research Center for Eco-Environmental Sciences, Chinese Academy \\ of Sciences, Beijing, 100085, China
}

Received: 20 August 2010 - Published in Hydrol. Earth Syst. Sci. Discuss.: 8 September 2010

Revised: 13 January 2011 - Accepted: 13 January 2011 - Published: 26 January 2011

\begin{abstract}
Quantitative evaluations of the impacts of climate change on water resources are primarily constrained by uncertainty in climate projections from GCMs. In this study we assess uncertainty in the impacts of climate change on river discharge in two catchments of the Yangtze and Yellow River Basins that feature contrasting climate regimes (humid and semi-arid). Specifically we quantify uncertainty associated with GCM structure from a subset of CMIP3 AR4 GCMs (HadCM3, HadGEM1, CCSM3.0, IPSL, ECHAM5, CSIRO, CGCM3.1), SRES emissions scenarios (A1B, A2, B1, B2) and prescribed increases in global mean air temperature $\left(1{ }^{\circ} \mathrm{C}\right.$ to $6^{\circ} \mathrm{C}$ ). Climate projections, applied to semi-distributed hydrological models (SWAT 2005) in both catchments, indicate trends toward warmer and wetter conditions. For prescribed warming scenarios of $1{ }^{\circ} \mathrm{C}$ to $6^{\circ} \mathrm{C}$, linear increases in mean annual river discharge, relative to baseline (19611990), for the River Xiangxi and River Huangfuchuan are $+9 \%$ and $11 \%$ per $+1{ }^{\circ} \mathrm{C}$ respectively. Intra-annual changes include increases in flood (Q05) discharges for both rivers as well as a shift in the timing of flood discharges from summer to autumn and a rise (24 to 93\%) in dry season (Q95) discharge for the River Xiangxi. Differences in projections of mean annual river discharge between SRES emission scenarios using HadCM3 are comparatively minor for the River Xiangxi (13 to $17 \%$ rise from baseline) but substantial (73 to $121 \%$ ) for the River Huangfuchuan. With one minor exception of a slight $(-2 \%)$ decrease in river discharge projected using HadGEM1 for the River Xiangxi, mean annual river
\end{abstract}

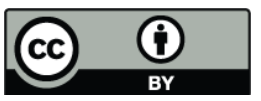

Correspondence to: $\mathrm{H} . \mathrm{Xu}$

(xuhm@cma.gov.cn) discharge is projected to increase in both catchments under both the SRES A1B emission scenario and $2^{\circ}$ rise in global mean air temperature using all AR4 GCMs on the CMIP3 subset. For the River Xiangxi, there is substantial uncertainty associated with GCM structure in the magnitude of the rise in flood (Q05) discharges ( -1 to $41 \%$ under SRES A1B and -3 to $41 \%$ under $2^{\circ}$ global warming) and dry season (Q95) discharges (2 to 55\% under SRES A1B and 2 to $39 \%$ under $2^{\circ}$ global warming). For the River Huangfuchuan, all GCMs project a rise in the Q05 flow but there is substantial uncertainty in the magnitude of this rise (7 to $70 \%$ under SRES $\mathrm{A} 1 \mathrm{~B}$ and 2 to $57 \%$ under $2^{\circ}$ global warming). Differences in the projected hydrological changes are associated with GCM structure in both catchments exceed uncertainty in emission scenarios. Critically, estimated uncertainty in projections of mean annual flows is less than that calculated for extreme (Q05, Q95) flows. The common approach of reporting of climate change impacts on river in terms of mean annual flows masks the magnitude of uncertainty in flows that are of most importance to water management.

\section{Introduction}

Global warming induced by rising concentrations of greenhouse gases is changing global climate patterns (Bates et al., 2008). Warming of the atmosphere observed over several decades is associated with the changes in hydrological systems globally and at the basin scale. These changes include: precipitation patterns and extremes; the amount and generation of river flow; the frequency and intensity of flood and drought; and, by extension, the quantity and quality of

Published by Copernicus Publications on behalf of the European Geosciences Union. 
freshwater resources (Xu and Singh, 2004; Juen et al., 2007). The magnitude and spatial distribution of changes in climate combined with characteristics of specific basins determine which impacts are the most important at a regional scale (Menzel, 2002; Matondo et al., 2004; Wilby et al., 2006; Hagg et al., 2007).

China has experienced changes in climate that include rising air temperatures and more variable precipitation. Such changes have been linked to an increased occurrence of flood events in southern China and more frequent droughts in northern China (Wang et al., 2005). The most important and direct impact of climate change is changes to the availability of water resources. Previous research indicates that the discharge of large rivers in China has decreased since 1950 along with more frequent drought and flood events (Zhang et al., 2007; Wang et al., 2008).

The Yangtze River and Yellow River are historically, culturally, and economically of critical importance to Southern and Northern China. The Yangtze River is $6300 \mathrm{~km}$ long and has a basin area 1.8 million $\mathrm{km}^{2}$ which primarily experiences a subtropical, monsoon climate. The Yellow River is $5464 \mathrm{~km}$ long and has a basin area of 0.8 million $\mathrm{km}^{2}$, that mainly comprises arid and semi-arid environments. The contrasting climates and landscapes of these basins give rise to very different hydrological regimes. The inter-comparison of responses in both basins to climate change is, therefore, expected to be indicative of many regions in China.

Mean annual precipitation in the Yangtze River basin is about $1070 \mathrm{~mm}$ and mean annual river discharge is $\sim 976 \mathrm{~km}^{3}$, equivalent to a specific discharge of $542 \mathrm{~mm}$. Annual per capita water availability decreased from $2700 \mathrm{~m}^{3}$ in 1980 to $2100 \mathrm{~m}^{3}$ in 2005 . Previous studies (Zhang et al., 2006, 2008; Jiang et al., 2007) show that there has not been a significant change in annual precipitation but an increase in the number of extreme (10th percentile) precipitation events is observed (Su et al., 2008). Greater variability in precipitation has intensified floods and prolonged droughts. Spatial and seasonal changes in precipitation have also been observed. Increased precipitation has been detected in middle and lower reaches of the Yangtze River in summer whereas a decrease in precipitation is observed in the upper reaches of the basin near the Three Gorges Dam site in autumn (Xu et al., 2008). Although no significant trend was detected for annual runoff in the Yangtze River basin during 1961-2000, a significant positive trend in flood discharges was found in the middle and lower basin over the same period.

Mean annual precipitation in the Yellow River is $470 \mathrm{~mm}$ and mean annual river discharge is $\sim 58 \mathrm{~km}^{3}$, equivalent to a specific discharge of $73 \mathrm{~mm}$. The basin can be classified as water scarce as this river discharge represents annual per capita water availability of less than $1000 \mathrm{~m}^{3}$ (Pereira et al., 2007). Previous studies (Fu et al., 2004; Liu et al., 2008; Huang et al., 2009) indicate trends toward higher air temperatures in the Yellow River basin during the past 50 years. Fu et al. (2004) find no significant trend in annual precipitation from 1951 to 1998 whereas others (Xu and Zhang, 2006; Liu et al., 2008; Huang et al., 2009) indicate precipitation has decreased over slightly different time periods (1961-2006, 1957-2006, and 1951-2000). Declines are especially apparent in spring, summer and autumn as well as preferentially in the southeastern part of the basin. These decreases are calculated after allowing for human uses (Fu et al., 2004; Wang et al., 2006). Applying climate projections generated from four GCMs (HadCM3, CGCM2, CCSR and CSIRO) for one emission scenario (SRES B2), Xu et al. (2009) estimate a reduction mean annual streamflow over the period 2010 to 2099 in a headwater catchment of the Yellow River Basin.

Current understanding of impacts of climate change on water resources is complicated by uncertainty in both climate projections and the simulation of hydrological responses to climate perturbations (Prudhomme et al., 2003; Treut et al., 2008; Minvill et al., 2008). The main objective of this study is to quantify uncertainty in climate change impacts on river discharge, in two sub-catchments of the Yangtze and Yellow River basins under contrasting climate regimes (semi-arid, humid). The hydrological model used here is Soil and Water Assessment Tool (SWAT) model, which is a physically based semi-distributed hydrological model that operates on a daily time step. Baseline climate that derives from detrended monthly CRU TS3.0 datasets (Mitchell and Jones, 2005) for the period during 1961-2005, were used for calibrating and validating the SWAT model. We quantify uncertainty in projections of climate change on river discharge by applying a range of climate scenarios using different GCMs (subset of IPCC AR4 GCMs), emission scenarios (SRES A1B A2, B1, B2) and prescribed increases in global mean air temperature ( 1 to $6{ }^{\circ} \mathrm{C}$ ), including the $2{ }^{\circ} \mathrm{C}$ threshold of 'dangerous' climate change (Todd et al., 2010). Daily climate datasets used to drive SWAT model were generated by a weather generator (Arnell, 2003).

\section{Study area and datasets}

\subsection{Basin description}

The River Xiangxi and River Huangfuchuan were selected as meso-scale catchments representative of the humid and semi-arid climates that predominate across the Yangtze and Yellow River basins, respectively. The River Xiangxi is one of the longest tributaries supplying the Three Gorges Reservoir (TGR) in Hubei Province. Eutrophication in the River Xiangxi strongly influences water quality in the TGR. The River Huangfuchuan is responsible for substantial soil erosion with annual sediment yields of $\sim 50$ million tonnes to Yellow River. The location of the two sub-catchments is shown in Fig. 1; physical characteristics of both are given in Table 1. The River Xiangxi is $94 \mathrm{~km}$ long and originates in the Shennongiia forest region with a catchment area of $3099 \mathrm{~km}^{2}$. The River Huangfuchuan is $137 \mathrm{~km}$ long 

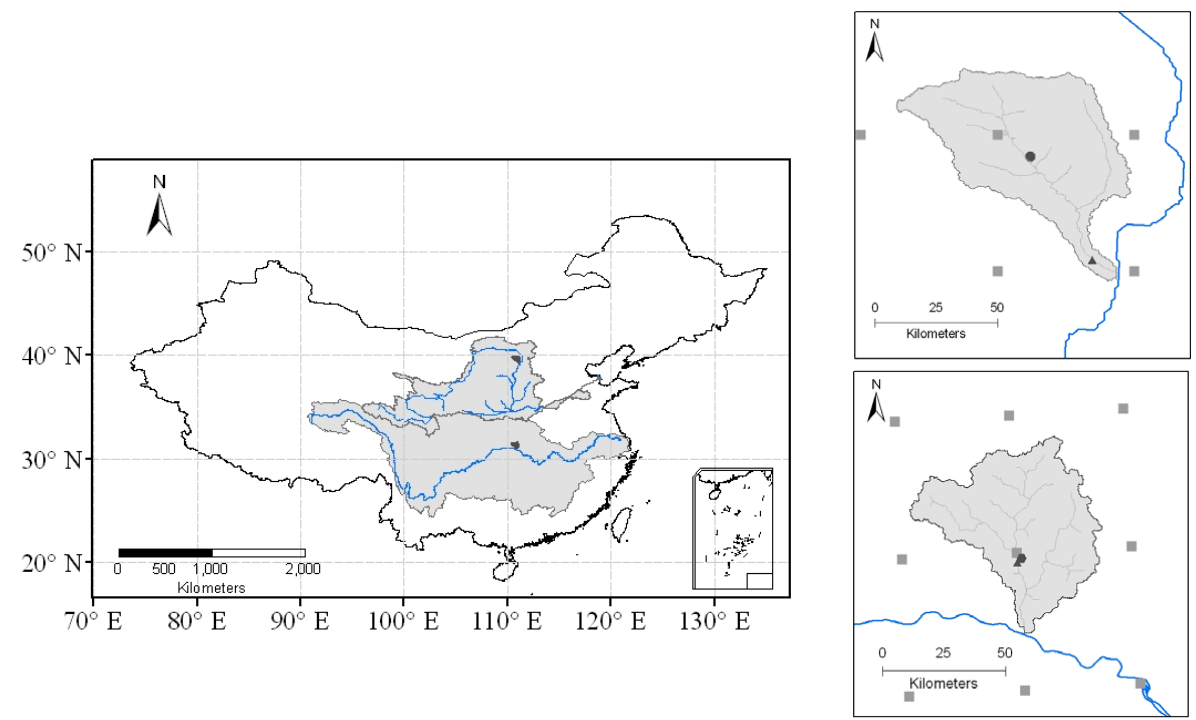

Fig. 1. Location of selected sub-catchments in the Yangtze and Yellow River Basins and climate stations (black circle), discharge stations (black triangle), and Climate Research Unit (CRU) grid nodes (grey square).

Table 1. Characteristics of the study catchments.

\begin{tabular}{lll}
\hline & Huangfuchuan & Xiangxi \\
\hline Location & & \\
\hline $\begin{array}{l}\text { River system } \\
\text { Latitude }\end{array}$ & Yellow River & Yangtze River \\
Longitude & $39.2^{\circ} \sim 39.9^{\circ} \mathrm{N}$ & $\begin{array}{l}31.0^{\circ} \sim 31.7^{\circ} \mathrm{N} \\
110.3^{\circ} \sim 111.2^{\circ} \mathrm{E}\end{array}$ \\
$110.5^{\circ} \sim 111.1^{\circ} \mathrm{E}$ \\
\hline Topography & & \\
\hline Elevation range $(\mathrm{m})$ & $836-1458$ & $100-3072$ \\
Catchment size $\left(\mathrm{km}^{2}\right)$ & 3246 & 3099 \\
\hline Climate & & \\
\hline Climate region & Semi-arid & humid \\
Mean annual precipitation $(\mathrm{mm})$ & 388 & 1100 \\
Mean annual temperature $\left({ }^{\circ}\right)$ & 7.5 & 15.6 \\
\hline Runoff & & \\
\hline Annual mean $(\mathrm{mm})$ & 53 & 688 \\
\hline
\end{tabular}

that encompasses the transition from the Erdos Desert to the Loess Plateau with a catchment area of $3246 \mathrm{~km}^{2}$.

The River Xiangxi catchment lies in the subtropical region and experiences a humid climate near the Three Gorges Dam. Mean annual precipitation observed from 1961 to 2004 is $1100 \mathrm{~mm}$ and is characterised by a dry winter and a summer monsoon from May to September. Mean annual air temperature from 1961 to 2004 is $15.6^{\circ} \mathrm{C}$ and ranges from $12^{\circ} \mathrm{C}$ to $20^{\circ} \mathrm{C}$. The River Xiangxi catchment is typical of northern sub-tropic landscapes with high relief. Mountainous areas are covered by forests. The main agricultural crops (rice, wheat) are grown in valleys. Terraced fields are often used for corn, potatoes and tea. Limestone soils predominate in headwater areas whereas brown and yellow-brown soils occur in the lowlands. The shallow soils with low humus content promote erosion and transport of particle-bound $P$ as well as leaching of soluble $\mathrm{N}$-fractions by interflow and surface runoff. To prevent soil erosion, terraces and mulching are practised but substantial nutrient fluxes to the river contribute to eutrophication.

The River Huangfuchuan has a semiarid climate and features pastoral farming in Northern China. Mean, annual precipitation observed from 1961 to 2000 is $388 \mathrm{~mm}$. Mean annual air temperature from 1961 to 2000 is $7.5^{\circ} \mathrm{C}$ and ranges from $6.9^{\circ} \mathrm{C}$ and $9.7^{\circ} \mathrm{C}$. The River Huangfuchuan is representative of the "hill-gully" landscape of the northern Loess Plateau. The watershed is mainly covered by grassland or bush land with fragmentary woodland. The main agricultural crops, maize and millet, are grown in the sloping cultivated land. The soils are subject to considerable water and wind erosion. The River Huangfuchuan which has experienced soil erosion and land desertification, is considered to be comparatively vulnerable to climate change.

\subsection{Available data}

Spatial data used in the study include a digital elevation model (DEM), land use, soil type, and climatic data. A digital elevation model with a scale of 1: 250000 was prepared by the China Fundamental Geographic Information Center. Spatial soil data with a scale of 1:1000 000 derive from Environment and Ecology Scientific Data Center of western China, National Natural Science Foundation of China. Soil properties were generated from the Soil Attribute Data Set which based on "Soil Species of China" and other sources with total information includes 7300 soil profiles collected 
Table 2. Mean and stand deviation (SD) of the posterior distribution resulting from application of the ParaSol technique.

\begin{tabular}{lcrrcrcc}
\hline Parameters & Canmx & Esco & Ch_K2 & Surglag & CN2 & Biomix & Alpha_BF \\
\hline Mean & 0.46 & 0.83 & 141.77 & 4.24 & 43.71 & 0.11 & 0.89 \\
SD & 0.60 & 0.19 & 8.49 & 1.98 & 8.02 & 0.14 & 0.09 \\
\hline
\end{tabular}

For description of the parameters see Xu et al. (2010).

from all over China. Land use is an important input parameter to SWAT as it influences runoff generation (Wu and Johnston, 2007). There is, however, limited land-use data for both catchments. Modelling of baseline and projected river discharge consequently do not consider changes in land-use and it as acknowledged that some disparities between simulated and observed discharge may be attributable to landuse change during the simulation period. The most recent land-use maps for the River Xiangxi compiled by the Hubei Land Management Bureau in the 1990s, were used to represent catchment land use. In the River Huangfuchuan, natural vegetative cover of grassland and woodland was converted to farmland from the 1950 s to 1970 s; restoration of artifical grassland and bush land has occurred since the late 1990s. Land-use records from the Inner Mongolia Autonomous Region Department of Land and Resource in the 1980s were used to represent catchment land use.

Monthly streamflow records for the Xiangshan gauging station of River Xiangxi and Huangfu gauging station of River Huangfuchuan were obtained from Water Year Books and are available for periods 1961-1994 and 1954-1997 respectively. Climate data used in this study during 19612005 are gridded $\left(0.5^{\circ} \times 0.5^{\circ}\right)$ CRU TS3.0 monthly datasets (Mitchell and Jones, 2005), which included monthly precipitation total and monthly average as well as maximum and minimum air temperatures.

\section{Methodology}

\subsection{Hydrological model: SWAT}

The Soil and Water Assessment Tool (SWAT) model is a physically based, semi-distributed, basin scale, continuoustime hydrological model that operates on a daily time step. In SWAT, basins are divided into multiple subwatersheds which are further subdivided into hydrologic response units (HRUs) that consist of homogeneous land use, management, and soil characteristics. The overall hydrological balance is simulated for each HRU including precipitation, irrigation water, infiltration, soil water redistribution, evapotranspiration, lateral subsurface flow, and return flow (Gassman et al., 2007). Applications of SWAT occur worldwide and include direct assessments of anthropogenic, climate change and other influences on a wide range of water resources. In China, SWAT has been used to simulate river discharge and sediment transport in sub-catchments of the Yellow River such as the Lushi and Heihe rivers for sediment simulation (Hao et al., 2004; Cheng et al., 2007), and in sub-catchments of Yangtze River such as Poyang Lake and small watershed in the TGR area for streamflow and soil erosion simulation (Guo et al., 2008; Shen et al., 2009).

\subsection{Calibration and validation of hydrological model}

Model parameterization was specified using the Arcview GIS interface for SWAT. The Xiangxi and Huangfuchuan catchments were divided respectively into 10 and 13 subwatersheds based on the DEM and the location of river gauging stations. After considering land use and soil characteristics, the River Xiangxi catchment was divided into 195 HRUs and River Huangfuchuan was divided into 314 HRUs. Potential evapotranspiration was calculated using the Hargreaves function (Hargreaves et al., 1985); surface runoff was estimated by a modification of the SCS curve number method (USDA-NRCS, 2004), and routing processes were estimated by the Muskingum method (Neitsch et al., 2005).

The employed SWAT model had recently been calibrated and validated for the River Xiangxi using monthly river discharge observations for the periods 1970-1974 and 1976-1986 (Xu et al., 2010). The ParaSol autocalibration routine (van Griensven and Meixner, 2007) embedded in AVSWAT2005 was used to improve the fit between simulated and observed discharge and to assess parameter uncertainty. Autocalibration considered the seven most sensitive parameters in the hydrological model. Summary statistics are reported in Table 2. Each parameter solutions shows very similarly good values of the Nash-Sutcliffe efficiency $\left(E_{\mathrm{ns}}\right)$ (not shown) and small standard deviations of the estimated model parameters (Table 2). In this study, the SWAT models were re-calibrated for 1961-1990 baseline period using monthly river discharge from Xiangshan gauging station of River Xiangxi and Huangfu gauging station of River Huangfuchuan, and validated with recent monthly river discharge data (1991-1994 Xiangxi; 1991-1997 Huangfuchuan). The performance of the SWAT2005 model was evaluated using statistical analyses to compare the quality and reliability of the predicted discharge with observed records. Summary statistics included the mean discharge $(Q)$, coefficient of determination $\left(R^{2}\right)$, and Nash-Sutcliffe efficiency $\left(E_{\mathrm{ns}}\right)$. The 
Table 3. Goodness of fit for SWAT simulations in River Xiangxi and River Huangfuchuan $\left(Q_{\mathrm{obs}}\right.$ and $Q_{\text {sim }}$ are observed and simulated mean monthly discharge in $\mathrm{m}^{3} \mathrm{~s}^{-1}$ ).

\begin{tabular}{lcccccccccc}
\hline & \multicolumn{4}{c}{ Huangfuchuan } & & \multicolumn{5}{c}{ Xiangxi } \\
\cline { 2 - 7 } \cline { 7 - 9 } & $Q_{\text {obs }}$ & $Q_{\text {sim }}$ & $E_{\mathrm{ns}}$ & $R^{2}$ & & $Q_{\text {obs }}$ & $Q_{\text {sim }}$ & $E_{\mathrm{ns}}$ & $R^{2}$ \\
\hline Calibration & 3.2 & 4.4 & 0.64 & 0.61 & & 34.1 & 32.2 & 0.43 & 0.44 \\
Validation & 4.8 & 5.1 & 0.66 & 0.66 & & 40.1 & 37.1 & 0.56 & 0.57 \\
\hline
\end{tabular}

observed and modelled flow duration curve and monthly discharge for the 1961-1994 period for River Xiangxi and 1961-1997 period for River Huangfuchuan are presented in Fig. 2. The calibrated SWAT model was used in the climate scenarios modeling for the two sub-catchments.

Model performance over the calibration and validation periods is generally acceptable, with efficiencies ranging from 0.61 to 0.66 for River Huangfuchuan and 0.43 to 0.56 for River Xiangxi (Table 3). The performance statics $E_{\mathrm{ns}}$ and $R^{2}$ are poorest for River Xiangxi in the calibration period with 0.43 and 0.44 respectively. Simulated mean monthly river discharge is overestimated (37\% and 6\%) for the River Huangfuchuan and underestimated (6\% and 7\%) for the River Xiangxi over both calibration and validation periods. The frequency distributions of simulated river discharge in both sub-catchments closely approximates those of the observed discharge records as indicated by flow duration curves. Peak flows of the River Xiangxi are very slightly underestimated (Fig. 2a and b). The model is capable of reproducing the observed flow for River Xiangxi (1961-1994) and Huangfuchuan (1961-1997) as showed in Fig. 2c and d.

\subsection{Climate change scenarios}

The generally good performance over the calibration and validation periods, suggest that the model can be used to simulate the impact of climate change scenarios. In addition to assessing projected changes in mean annual river discharge, we also changes in high and low monthly runoff, expressed as Q05 and Q95 respectively, where for example, Q05 is the runoff exceeded only $5 \%$ of the time.

Climate projections for temperature and precipitation were generated using the ClimGen pattern-scaling technique described in Osborn (2009) and Todd et al. (2010). Scenarios were generated for (1) greenhouse-gas emission scenarios (A1B, A2, B1, B2) and (2) prescribed increases in global mean temperature of $1,2,3,4,5$, and ${ }^{\circ} \mathrm{C}$ using the UKMO HadCM3 GCM as well as (3) A1B emission scenario and prescribed warming of $2{ }^{\circ} \mathrm{C}$ ("dangerous" climate change) using six additional GCMs from the World Climate Research Programme (WCRP) Coupled Model Intercomparison Project phase 3 (CMIP3) multi-model dataset: CCCMA CGCM3.1, CSIRO Mk30, IPSL CM4, MPI ECHAM5, NCAR CCSM3.0, and UKMO HadGEM1.
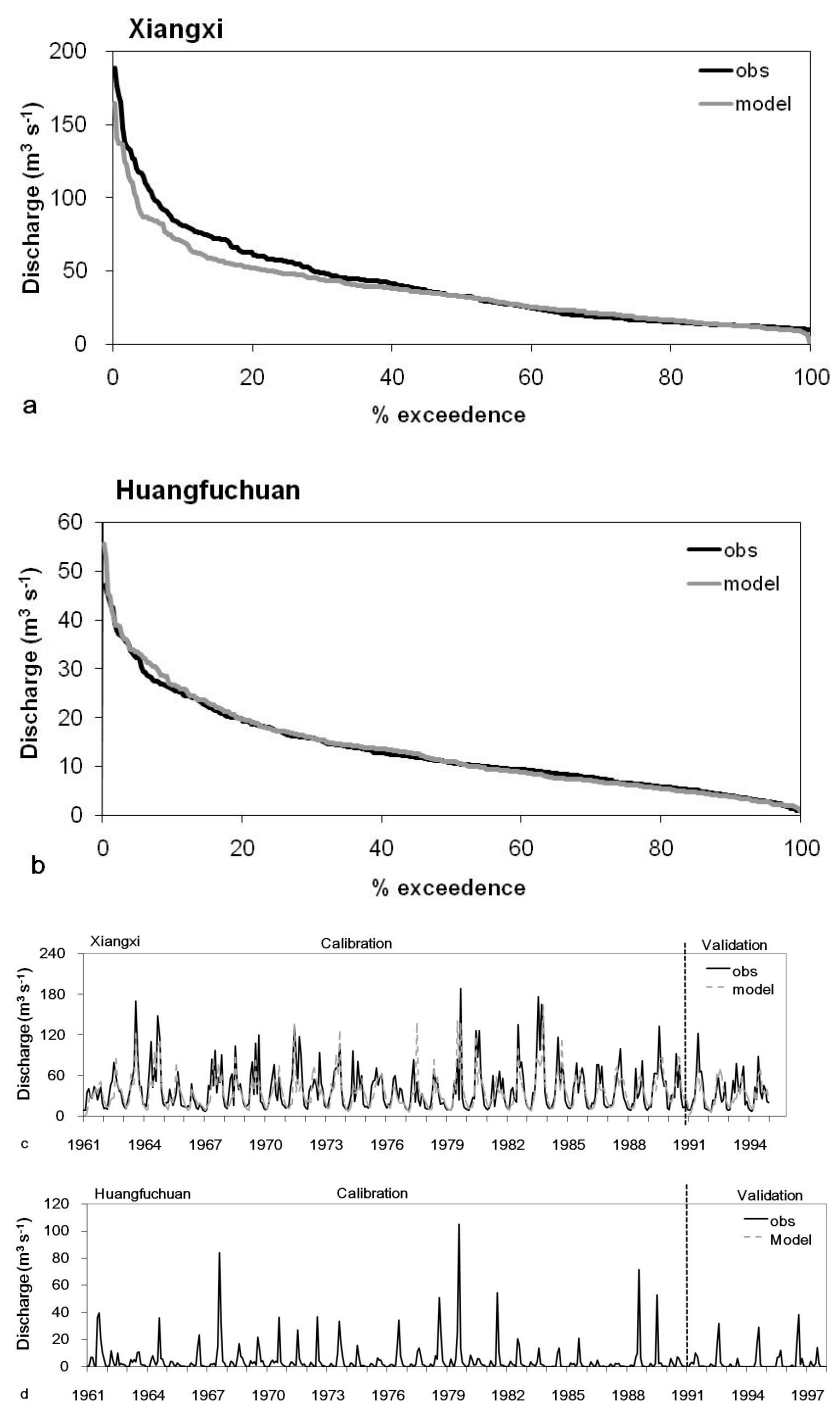

Fig. 2. Observed and simulated river discharge in River Xiangxi - 1961-1994, (a) flow duration curve; (c) monthly discharge and River Huangfuchuan for 1961-1997, (b) flow duration curve, (d) monthly discharge. 

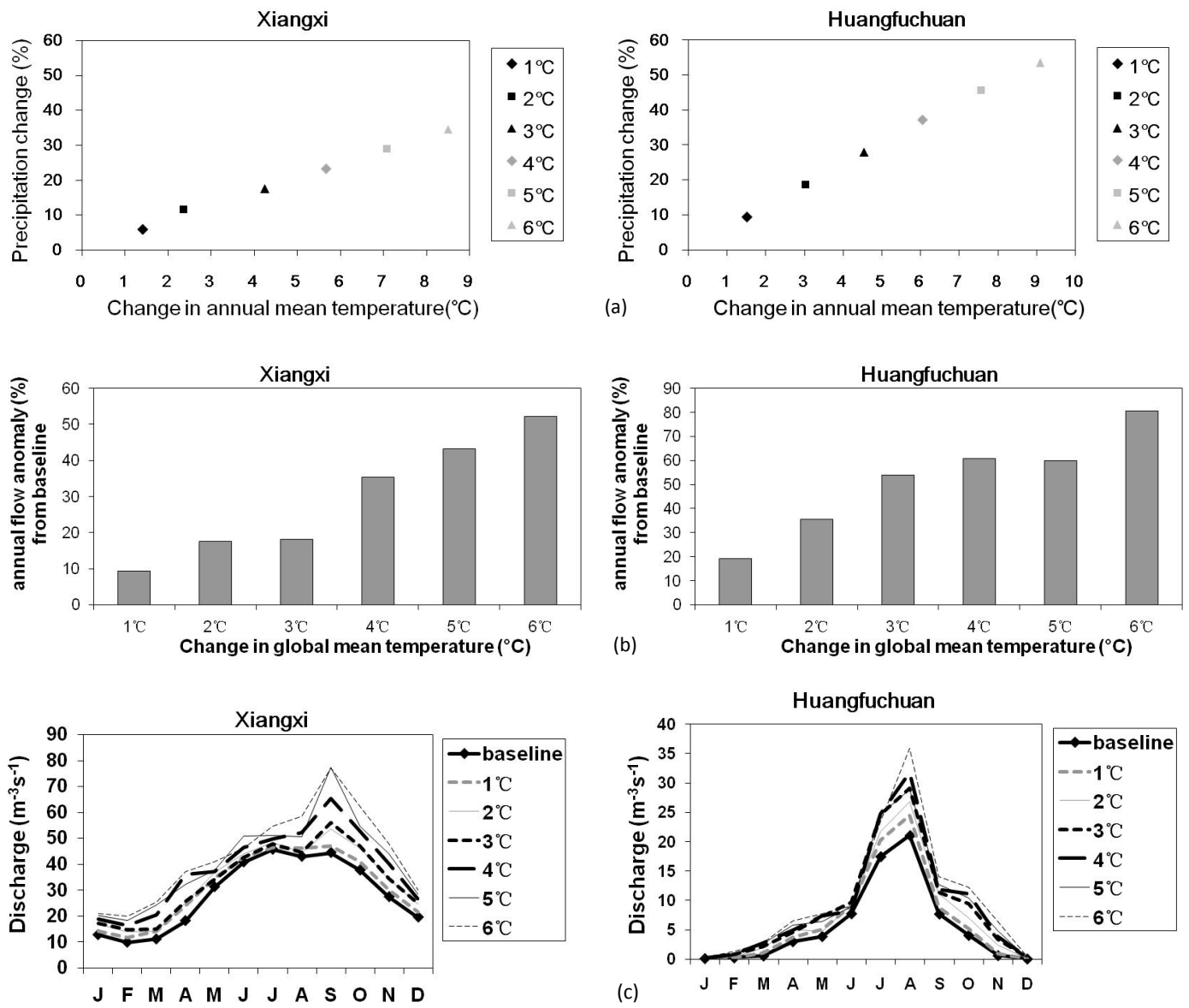

Fig. 3. (a) Projected changes in annual mean temperature $\left(^{\circ}\right)$ and annual precipitation $(\%)$, (b) annual and (c) monthly discharge for HadCM3 prescribed warming scenarios.

\section{Results}

\subsection{Uncertainty in the magnitude of prescribed increases in global mean air temperature}

Figure 3a indicates that for the chosen sub-basins precipitation is projected by HadCM3 to increase at a near-linear rate with a rise in global mean air temperature of $1{ }^{\circ} \mathrm{C}$ to $6^{\circ} \mathrm{C}$. Annual precipitation is projected to increase, relative to baseline, by $6 \%$ to $35 \%$ for the River Xiangxi and $9 \%$ to $53 \%$ for the River Huangfuchuan. Along with linear increases in precipitation, preferential increases in air temperature relative to global mean are also projected (e.g. $8.5^{\circ} \mathrm{C}$ in River Xiangxi and $9.1^{\circ} \mathrm{C}$ in River Huangfuchuan for a $6^{\circ} \mathrm{C}$ rise in global mean air temperature (Fig. 3a).

Mean annual river discharge is estimated to increase in both the Xiangxi and Huangfuchuan catchments under prescribed increases in global mean air temperature projected by HadCM3 (Fig. 3b). Increases in mean annual river discharge with rising air temperatures are, however, non-linear (Fig. 3b). Under rises of $1{ }^{\circ} \mathrm{C}$ to $3{ }^{\circ} \mathrm{C}$, the trend in rising river discharge for the River Xiangxi is lower than that estimated for warming of $4{ }^{\circ} \mathrm{C}$ to $6{ }^{\circ} \mathrm{C}$; the reverse is observed for the River Huangfuchuan. Substantial changes in intra-annual river discharge are associated with the non-linear response in annual river discharge to increasing global mean air temperature (Fig. 3c). Monthly flow is projected to increase in all months and there is a shift in flood season (high flows) from summer to autumn for the River Xiangxi. The low (Q95) flow increases dramatically ( $24 \%$ to $93 \%$ ) for the River Xiangxi and the high (Q05) flow increases substantially (13\% to $64 \%$ ) but in a non-linear fashion for the River Huangfuchuan.

\subsection{Uncertainty associated with different SRES emissions scenarios}

Figure $4 \mathrm{a}$ shows the changes in mean climate projected by HadCM3 for each of the four SRES scenarios (A1B, B1, B2, A2) in both study catchments. Increases in mean annual temperature range from $2.5^{\circ}$ to $3.4^{\circ}$ for the River Xiangxi and from $2.7^{\circ}$ to $3.6^{\circ}$ for the River Huangfuchuan. The highest increases occur under the A1B emission scenario for both basins. Projected precipitation increases by $\sim 10 \%$ with little variance between emission scenarios for the River Xiangxi. 

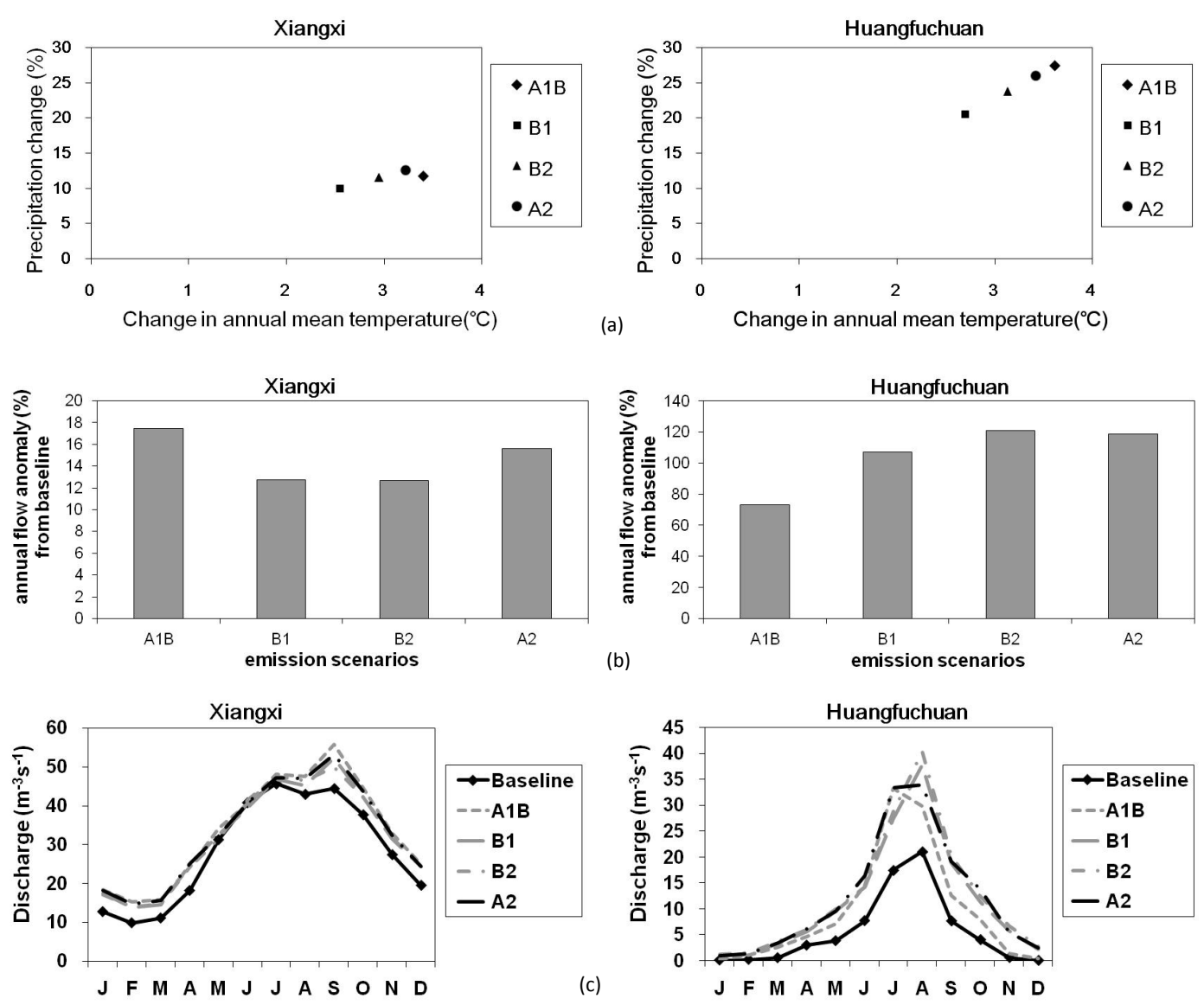

Fig. 4. (a) Projected changes in annual mean temperature $\left({ }^{\circ}\right)$ and annual precipitation (\%), (b) annual and (c) monthly discharge for HadCM3 different emission scenarios.

For the River Huangfuchuan, precipitation is projected to increases by 20 to $28 \%$ relative to baseline with slightly greater differences between the four emission scenarios. These projected changes in climate give rise to substantially different increases in river discharge (Fig. 4b). The magnitude of changes for annual discharge varies from 13 to $17 \%$ for the River Xiangxi and from 73 to $121 \%$ for the River Huangfuchuan. The projected monthly discharge for River Huangfuchuan under different SRES emission scenarios increases throughout the year (Fig. 4c). There is only minor uncertainty in the magnitude for the rise in the Q05 flow (10 to $17 \%$ ) and the Q95 flow (45 to 55\%) for the River Xiangxi whereas high (Q05) flows increase considerably (70 to 90\%) for the River Huangfuchuan.

\subsection{Uncertainty in GCM structure for SRES A1B emission scenario}

Figure 5a shows the projected changes in climate under the A1B emission scenario for the priority subset of seven AR4 GCMs. The projected annual mean temperature increases for all GCMs under SRES A1B but ranges from approximately $2^{\circ}$ (CSIRO, HadGEM1 and CCSM3.0 GCM) to $3.4^{\circ}$ (HadCM3, IPSL and ECHAM5 GCM) for the River Xiangxi and from $\sim 2.2^{\circ}$ (CSIRO and CCSM3.0 GCM) to $3.8^{\circ}$ (HadCM3 and ECHAM5 GCM) for the River Huangfuchuan. Projected changes in mean annual precipitation for the River Xiangxi are minor ( $< \pm 2 \%$ from baseline) for three GCMs (CCSM3.0, CSIRO, ECHAM5) but show moderate increases of 7 to $12 \%$ for four GCMs (HadCM3, CGCM31, HadGEM1, IPSL). Projected changes in mean annual precipitation for the River Huangfuchuan are minor $(<5 \%$ from baseline) for two GCMs (CSIRO, ECHAM5), moderate (12 to $17 \%$ from baseline) for four GCMs (CCSM3.0, HadGEM1, CGCM3.1, IPSL) and substantial (27\%) for HadCM3. In contrast, there is considerably less variation in projected increases in annual mean temperature for both basins. Projected changes in precipitation between basins reveal large differences. For example, the CCSM3.0 GCM projects a decrease in precipitation of $-2 \%$ for River Xiangxi and an increase in precipitation of $+17 \%$ for the River Huangfuchuan. Indeed, this trend is robust as all GCMs project greater increases in precipitation for the River Huangfuchuan than the River Xiangxi. 

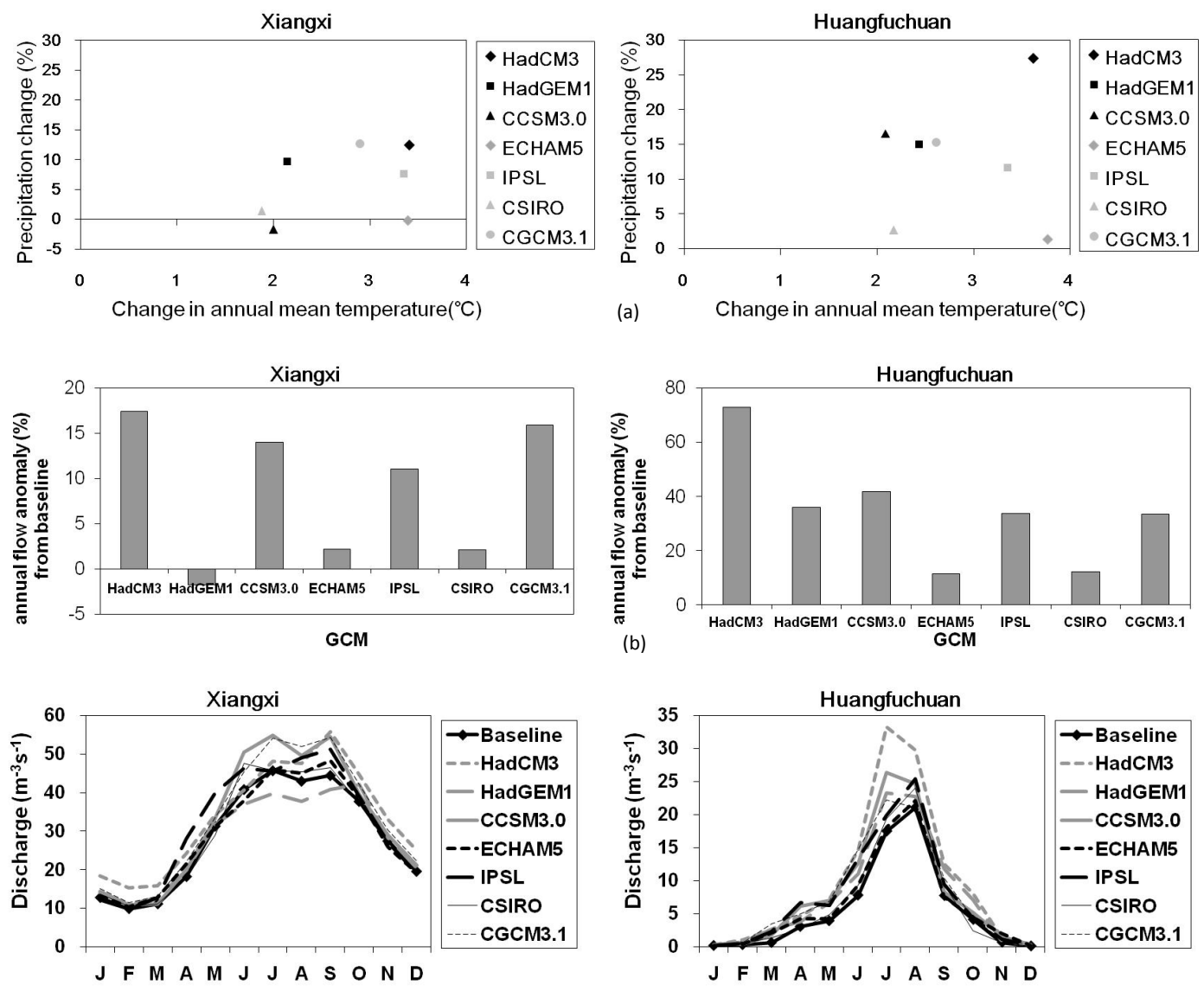

(c)

Fig. 5. (a) Projected changes in annual mean temperature $\left(^{\circ}\right)$ and annual precipitation $(\%)$, (b) annual and (c) monthly discharge under SRES A1B across 7 GCMs.

Following precipitation projections, hydrological modelling shows a consistent increase in river discharge for the two sub-basins though with substantial disparities between GCMs. HadGEM1 is the only GCM to project a decrease in annual mean discharge (Fig. 5b). For the River Xiangxi, the ensemble mean (of GCMs) is an increase of $9 \%$ in mean annual river discharge; HadGEM1 projects a decrease of $-2 \%$ in annual discharge whereas the other GCMs project increases ranging from 2 to $17 \%$. For the River Huangfuchuan, the ensemble mean is an increase of $34 \%$ in mean annual river discharge; HadCM3 projects the largest increase in mean annual discharge (73\%) whereas the other GCMs project increases ranging from 11 to $42 \%$.

Relative to projected changes in mean annual river discharge, there is less consistency in projections of intra-annual river discharge in both catchments (Fig. 5c). For the River Xiangxi, all GCMs project a rise in the low (Q95) flow but they range from 2 to $55 \%$. There is also a near-uniform rise (HadGEM1 excepted) in projections of high (Q05) flows but there is substantial uncertainty in the magnitude of these rises for the River Xiangxi ( -1 to $41 \%$ ) and River Huangfuchuan (7 to $70 \%$ ).

\subsection{Uncertainty in GCM structure for $2^{\circ}$ rise in global mean air temperature}

Uncertainty in projected changes in climate under a $2^{\circ}$ rise in global mean air temperature associated with the priority subset of AR4 GCMs is shown in Fig. 6a. Preferential increases in mean, annual temperature are evident in both the River Xiangxi and River Huangfuchuan. The rise ranges from $2.2^{\circ}$ for the HadGEM1 GCM to $2.8^{\circ}$ for the IPSL GCM in River Xiangxi. For the River Huangfuchuan, the rise ranges from $2.3^{\circ}$ for CGCM31 GCM to $3.0^{\circ}$ for HadCM3 GCM. Differences between GCMs in projections of mean annual precipitation are greater than that for temperature. Projected changes in mean annual precipitation, relative to baseline, vary from a $-2 \%$ decrease for HadGEM1 to a $12 \%$ increase for HadCM3 in River Xiangxi and from a 1 to $19 \%$ increases for ECHAM5 and CCSM3.0 GCMs respectively for the River Huangfuchuan.

An increase in mean annual river discharge in both basins under a $2{ }^{\circ} \mathrm{C}$ rise in global mean air temperature is a robust projection using all GCMs (Fig. 6b) except HadGEM1 (slight decrease). For the River Xiangxi, the ensemble mean 

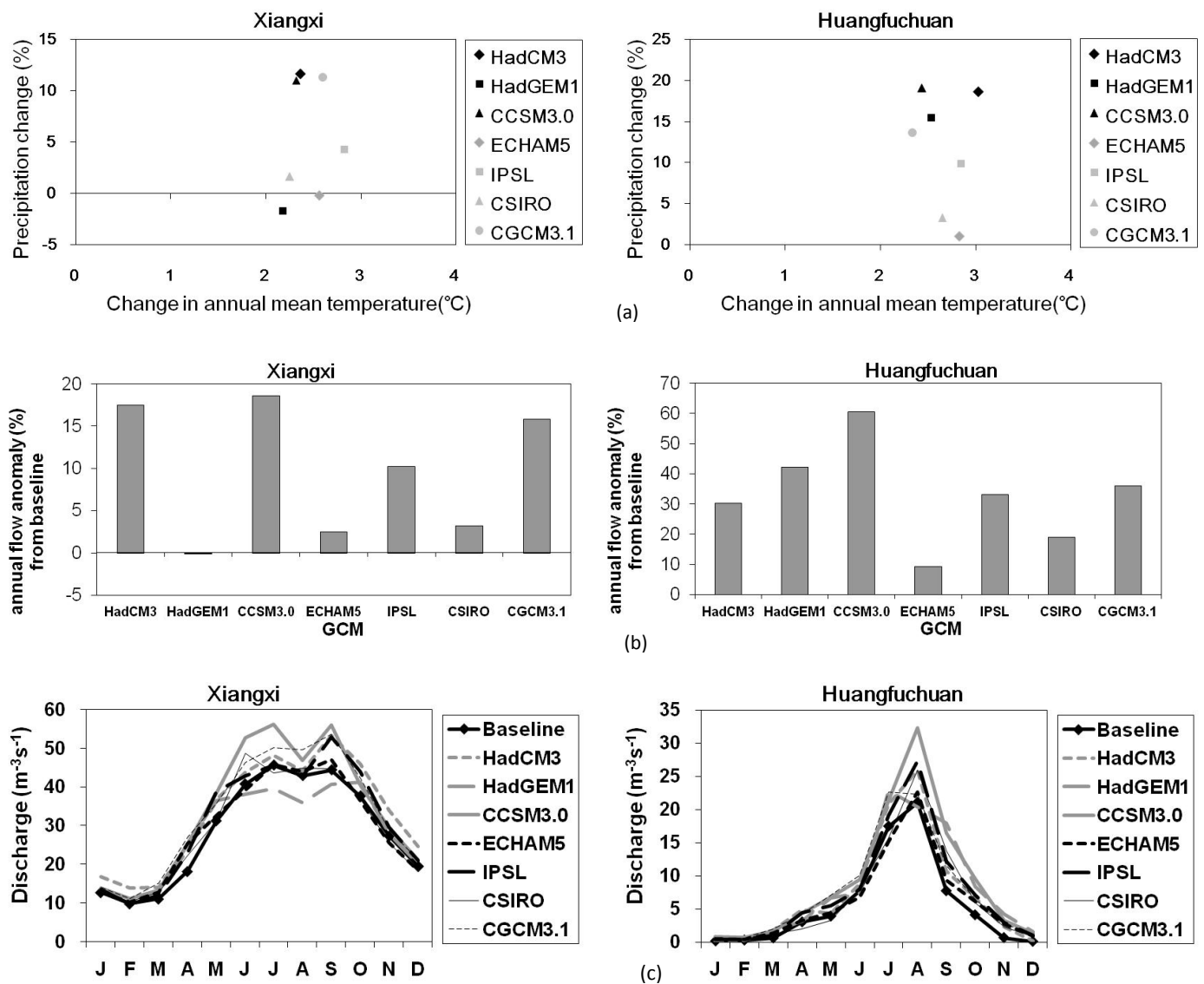

Fig. 6. (a) Projected changes in annual mean temperature $\left(^{\circ}\right)$ and annual precipitation $(\%)$, (b) annual and (c) monthly discharge under $2^{\circ}$ warming scenarios across 7 GCMs.

projection (of GCMs) is an increase in mean annual discharge of $10 \%$ relative to baseline and ranges from $2.5 \%$ for ECHAM5 to $19 \%$ for CCSM3.0. For the River Huangfuchuan, the ensemble mean projection is a $33 \%$ increase in mean annual river discharge which ranges from $9 \%$ for ECHAM5 to $60 \%$ for CCSM3.0. Projected intra-annual (seasonal) changes in river discharge for the River Huangfuchuan indicate an earlier (July) peak flow relative to baseline (August) for CGCM31 and HadCM3 and an increase in peak discharges in July for the other GCMs (Fig. 6c). All GCMs project a rise in the Q05 flow but there is uncertainty in the magnitude of this rise (2 to 57\%) for River Huangfuchuan. For the River Xiangxi, all GCMs with one exception (HadGEM1) project a rise in the Q05 flow (Fig. 6c); uncertainty ranges from -3 to $41 \%$. Uncertainty in the magnitude of the rise in the Q95 flow ranges from 2 to $39 \%$.

\section{Discussion}

The assessment of the impacts of climate change on river discharge in a humid subtropical sub-basin of the Yangtze River and a semi-arid temperate sub-basin of the Yellow River reveals near-uniformity in projections of greater mean annual river discharge. There is, however, substantial uncertainty in the magnitude of projected increases in river discharge that is primarily associated with GCM structure, magnitude of global warming, and emission scenarios. The greatest uncertainty in the projected changes in river discharge stems from the choice of GCM from the priority subset of seven AR4 GCMs. With the exception of projections of a slight $(-2 \%)$ decrease in river discharge from HadGEM1, mean annual river discharge increases under both the SRES A1B emission scenario and $2^{\circ}$ rise in global mean air temperature irrespective of the applied GCM. This finding is unique among the catchments examined on five continents reported in this special issue (Arnell, 2010; Hughes et al., 2010; Kingston and Taylor, 2010; Kingston et al., 2010; Nobrega et al., 2010; Singh et al., 2010; Thorne, 2010). Differences in hydrological projections between the SRES emission scenarios projected by HadCM3 are comparatively minor (13 to $17 \%$ increase relative to baseline) for the River Xiangxi but substantial for the River Huangfuchuan (73 to $121 \%$ increase relative to baseline). The differences result primarily from differences in projections of precipitation in both basins. 
Warmer and wetter scenarios for the River Huangfuchuan are projected to increase river discharge substantially which, if properly managed, could serve to alleviate current water scarcity. The projected increase in peak flows (Q05) in the River Huangfuchuan serves to exacerbate soil erosion. The general increase in peak flow (Q05) and low flow (Q95) in River Xiangxi is expected to increase the fluxes of non-point source pollution and sediment to river channel by runoff. Increased river discharge could serve to dilute point-source pollution and increase the likelihood that environmental flows are realized (Shao et al., 2008; Li et al., 2009). Increasing river discharge has important implications for the management of water resources in both catchments. Increases in mean flow expand available water resources but the rise in peak flows (Q05) in both basins will increase flood frequency and flood risk. Adaption measures need to consider projected changes in both mean and extreme (Q05, Q95) flows and uncertainties therein.

\section{Conclusions}

Uncertainty in the impact of climate change on river discharge in two representative catchments in the Yangtze River (Xiangxi) and the Yellow River (Huangfuchuan) basins associated with GCM structure, emissions scenarios and prescribed increases in global mean temperature has been quantified. The first notable conclusion from this work is the nearuniform consistency in the direction of the climate change signal of increased river discharge observed in both basins associated with seven CMIP3/IPCC-AR4 GCMs, four SRES emissions scenarios (A1B, A2, B1, B2), and prescribed increases of $1^{\circ} \mathrm{C}$ to $6^{\circ} \mathrm{C}$ in global mean air temperature. Substantially greater increases in river discharge relative to baseline are consistently projected for the semi-arid, River Huangfuchuan catchment in north China compared to the sub-tropical humid, River Xiangxi catchment in south China. There is, however, substantial uncertainty in the magnitude of projected increases in river discharge resulting from climate change. The greatest source of uncertainty in hydrological projections in both catchments is GCM structure (choice of GCMs). Our results provide an indication of the relative magnitude of uncertainty in current projections of hydrological change in sub-basins of the Yangtze River and the Yellow River, and highlight the importance of using multimodel (GCM) evaluations of climate change impacts on water resources. Although the priority subset of senven GCMs was specifically selected to represent the expected range of uncertainty in GCM projections, uncertainty would be expected to increase if a larger number of GCMs had been employed. Similar to other studies in this issue (Arnell, 2010; Kingston and Taylor, 2010; Thorne, 2010), noted differences in projections of mean river discharge and intra-annual (seasonal) flows question the representivity of using mean flows to represent hydrological change to water managers as changes in extreme flows (e.g. Q05, Q95) are far more critical.

Acknowledgements. This work was made possible by grants from the UK Natural Environment Research Council under the Quantifying and Understanding the Earth System (QUEST) programme (Ref. NE/E001890/1), Natural Science Foundation of China (NSFC, Ref. 40971022) and National Basic Research Program of China (973, Ref. 2010CB428401). The climate change scenarios were created with the ClimGen package, which was developed by Tim Osborn at the Climatic Research Unit (CRU) at the University of East Anglia (UEA), UK. Discussions and helpful insights of quantify uncertainties provided by participants of QUEST-GSI in study are also appreciated.

Edited by: J. Thompson

\section{References}

Arnell, N. W.: Effects of IPCC SRES* emissions scenarios on river runoff: a global perspective, Hydrol. Earth Syst. Sci., 7, 619641, doi:10.5194/hess-7-619-2003, 2003.

Arnell, N. W.: The relationship between climate forcing and hydrological response in UK catchments, Hydrol. Earth Syst. Sci. Discuss., 7, 7633-7667, doi:10.5194/hessd-7-7633-2010, 2010.

Bates, B. C., Kundzewicz, Z. W., Wu, S., and Palutikof, J. P.: Climate Change and Water, Technical Paper of the Intergovernmental Panel for Climate Change, IPCC Secretariat, Geneva, Switzerland, 2008.

Cheng, H., Ouyang, W., Hao, F., Ren, X., and Yang, S.: The nonpoint-source pollution in livestock-breeding areas of the Heihe River basin in Yellow River. Stoch. Environ. Res. Risk Assess., 21, 213-221, doi:10.1007/s00477-006-0057-2, 2007.

Fu, G. B., Chen, S. L., Liu, C. M., and Shepard, D.: Hydro-climatic trends of the Yellow River Basin for the last 50 years, Climatic Change, 65, 149-178, 2004.

Gassman, P. W., Reyes, M. R., Green, C. H., and Arnold, J. G.: The soil and water assessment tool: Historical development, applications and future research directions, T. ASABE, 50, 1211-1250, 2007.

Guo, H., Hu, Q., and Jiang, T.: Annual and seasonal streamflow responses to climate and land-cover changes in the Poyang Lake basin, China, J. Hydrol., 355, 106-122, 2008.

Hagg, W., Braun, L. N., Kuhn, M., and Nesgaard, T. I.: Modelling of hydrological response to climate change in glacierized central Asian catchments, J. Hydrol., 332, 40-53, 2007.

Hao, F. H., Zhang, X. S., and Yang, Z. F.: A distributed nonpointsource pollution model: Calibration and validation in the Yellow River basin, J. Environ. Sci., 16(4), 646-650, 2004.

Hargreaves, G. L., Hargreaves, G. H., and Riley, J. P.: Agricultural benefits for Senegal River basin, J. Irrig. Drain. E.-ASCE, 108(3), 225-230, 1985.

Huang, Y., Cai, J., Yin, H., and Cai, M.: Correlation of precipitation to temperature variation in the Huanghe River (Yellow River) basin during 1957-2006, J. Hydrol., 372, 1-8, 2009.

Hughes, D. A., Kingston, D. G., and Todd, M. C.: Uncertainty in water resources availability in the Okavango River Basin as a result of climate change, Hydrol. Earth Syst. Sci. Discuss., 7, 5737-5768, doi:10.5194/hessd-7-5737-2010, 2010. 
Jiang, T., Su, B., and Hartmann, H.: Temporal and spatial trends of precipitation and river flow in the Yangtze River basin, 19612000, Geomorphology, 85, 143-154, 2007.

Juen, I., Kaser, G., and Georges, C.: Modelling observed and future runoff from a glacierized tropical catchment (Cordillera Balanca, Peru), Global. Planet. Change, 59, 37-48, 2007.

Kingston, D. G. and Taylor, R. G.: Sources of uncertainty in climate change impacts on river discharge and groundwater in a headwater catchment of the Upper Nile Basin, Uganda, Hydrol. Earth Syst. Sci., 14, 1297-1308, doi:10.5194/hess-14-12972010, 2010.

Kingston, D. G., Thompson, J. R., and Kite, G.: Uncertainty in climate change projections of discharge for the Mekong River Basin, Hydrol. Earth Syst. Sci. Discuss., 7, 5991-6024, doi:10.5194/hessd-7-5991-2010, 2010.

Li, F., Cai, Q., Fu, X., and Liu, J.: Construction of habitat suitability odels (HSMs) for benthic macroinvertebrate and their applications to instream environmental flows: A case study in Xiangxi River of Three Gorges Reservoir region, China, Prog. Nat. Sci., 19, 359-367, 2009.

Liu, Q., Yang, Z., and Cui, B.: Spatial and temporal variability of annual precipitation during 1961-2006 in Yellow River Basin, China, J. Hydrol., 361, 330-338, 2008.

Matondo, J. I., Peter, G., and Msibi, K. M.: Evaluation of the impact of climate change on hydrology and water resources in Swaziland: Part II, Phys. Chem. Earth., 29, 1193-1202, 2004.

Menzel, L. and Bürger, G.: Climate change scenarios and runoff response in the mulde catchment (Southern Elbe, Germany), J. Hydrol., 267, 53-64, 2002.

Minville, M., Brissette, F., and Lecontem, R.: Uncertainty of the impact of climate change on the hydrology of a Nordic watershed, J. Hydrol., 358, 70-83, 2008.

Mitchell, T. and Jones, P.: An improved method of constructing a database of monthly climate observations and associated highresolution grids, Int. J. Climatol., 25, 693-712, 2005.

Neitsch, S. L., Arnold, J. G., Kiniry, J. R., and Williams, J. R.: Soil and Water Assessment Tool Theoretical Documentation, Version 2005, Temple, Tex.: USDA-ARS Grassland, Soil and Water Research Laboratory, available at: swatmodel.tamu.edu/media/ 1292/swat2005theory.pdf, last access: 1 November 2006, 2005.

Nóbrega, M. T., Collischonn, W., Tucci, C. E. M., and Paz, A. R.: Uncertainty in climate change impacts on water resources in the Rio Grande Basin, Brazil, Hydrol. Earth Syst. Sci. Discuss., 7, 6099-6128, doi:10.5194/hessd-7-6099-2010, 2010.

Osborn, T. J.: A user guide for ClimGen: a flexible tool for generating monthly climate data sets and scenarios, Climatic Research Unit, University of East Anglia, Norwich, 17 pp., 2009.

Pereira, L. S., Goncalves, J. M., Dong, B., Mao, Z., and Fang, S. X.: Assessing basin irrigation and scheduling strategies for saving irrigation water and controlling salinity in the upper Yellow River Basin, China, Agr. Water Manage., 93, 109-122, 2007.

Prudhomme, C., Jakob, D., and Svensson, C.: Uncertanity and climate impact on flood regime of small UK catchments, J. Hydrol., 277, 1-23, 2003.

Shao, M., He, L., Han, X., Xie, Z., Li, D., and Cai, Q.: Seasonal patterns of sedimentation and their associations with benthis communities in Xiangxi Bay of the Three Gorges Reservoir, China, J. Freshwater. Ecol., 23, 151-160, 2008.
Shen, Z. Y., Gong, Y. W., Li, Y. H., Hong, Q., Xu, L., and Liu, R. M.: A comparison of WEPP and SWAT for modeling erosion of the Zhangjiachong watershed in the Three Gorges Reservoir Area, Agr. Water. Manage., 96, 1435-1442, 2009.

Singh, C. R., Thompson, J. R., French, J. R., Kingston, D. G., and Mackay, A. W.: Modelling the impact of prescribed global warming on runoff from headwater catchments of the Irrawaddy River and their implications for the water level regime of Loktak Lake, northeast India, Hydrol. Earth Syst. Sci., 14, 1745-1765, doi:10.5194/hess-14-1745-2010, 2010.

Su, B., Gemmer, M., and Jiang, T.: Spatial and temporal variation of extreme precipitation over the Yangtze River Basin, Quatern. Int., 186, 22-31, 2008.

Thorne, R.: Uncertainty in the impacts of projected climate change on the hydrology of a subarctic environment: Liard River Basin, Hydrol. Earth Syst. Sci. Discuss., 7, 3129-3157, doi:10.5194/hessd-7-3129-2010, 2010.

Todd, M. C., Taylor, R. G., Osborne, T., Kingston, D., Arnell, N. W., and Gosling, S. N.: Quantifying the impact of climate change on water resources at the basin scale on five continents a unified approach, Hydrol. Earth Syst. Sci. Discuss., 7, 7485-7519, doi:10.5194/hessd-7-7485-2010, 2010.

Treut, H. L., Gastineau, G., and Li, L.: Uncertainties attached to global and local climate changes, C. R. Geosci., 340, 584-590, 2008.

USDA - NRCS: Part 630: Hydrology, Chapter 10: Estimation of direct runoff from storm rainfall: Technical references, in: NRCS National Engineering Handbook, Washington, DC, USDA National Resources Conservation Service, available at: www.wcc.nrcs.usda.gov/hydro/hydro-techref-neh-630.html, last access: 14 February 2007, 2004.

Van Griensven, A. and Meixner, T.: A global and efficient multiobjective auto-calibration and uncertainty estimation method for water quality catchment models, J. Hydroinform., 9, 277-291, 2007.

Wang, J. X., Zhang, J. Y., Li, Y., and Zhang, S. L.: Variation trends of runoffs seasonal distribution of the six large basins in China over past 50 years (in Chinese), Adv. Water. Sci., 19(5), 656-661, 2008.

Wang, S. W., Wu, R. S., and Yang, X. Q.: Chapter 2: climate change in China, in: Climate and Environment change in China (in Chinese), edited by: Qing, D. H., Ding, Y. H., Su, J. L., and Wang, S. M., Science Press, Beijing, China, 63-103, 2005.

Wilby, R. L., Whithhead, P. G., Wade, A. J., Butterfield, D., Davis, R. J., and Watts, G.: Integrated modeling of climate change impacts on water resources and quality in a lowland catchment: River Kennet, UK, J. Hydrol., 330, 204-220, 2006.

Wu, K. and Johnston, C. A.: Hydrologic response to climatic variability in a Great Lake Watershed: A case study with the SWAT model, J. Hydrol., 337, 187-199, 2007.

$\mathrm{Xu}$, C.-Y. and Singh, V. P.: Review on regional water resources assessment models under stationary and changing climate, Water. Resour. Manag., 18, 591-612, 2004.

Xu, H., Taylor, R., Kingston, D., Jiang, T., Thompson, J., and Todd, M.: Hydrological modeling of River Xiangxi using SWAT2005: a comparison of model parameterizations using station and gridded meteorological observations, Quatern. Int., 226, 54-59, doi:10.1016/j.quaint.2009.11.037, 2010. 
Xu, J., Yang, D., Yi, Y., Lei, Z., Chen, J., and Yang, W.: Spatial and temporal variation of runoff in the Yangtze River basin during the past 40 years, Quatern. Int., 186, 32-42, 2008.

$\mathrm{Xu}, \mathrm{Z}$. X. and Zhang, N.: Long-term trend of precipitation in the Yellow River Basin during the past 50 years (in Chinese), Geogr. Res., 25(1), 27-34, 2006.

$\mathrm{Xu}$, Z. X., Zhao, F. F., and Li, J. Y.: Response of streamflow to climate change in the head water catchment of the Yellow River basin, Quatern. Int., 208, 62-75, doi:10.1016/j.quaint.2008.09.001, 2009.
Zhang, J. Y., Zhang, S. L., Wang, J. X., and Li, Y.: Study on runoff trends of the six larger basins in China over the past 50 years (in Chinese), Adv. Water Sci., 18(2), 230-234, 2007.

Zhang, Q., Xu, C.-Y., Becker, S., and Jiang, T.: Sediment and runoff changes in the Yangtze River basin during past 50 years, J. Hydrol., 331, 511-523, 2006.

Zhang, Q., Xu, C.-Y., Zhang, Z. X., Chen, Y. D., Liu, C.-L., and Lin, H.: Spatial and temporal variability of precipitation maxima during 1960-2005 in the Yangtze River basin and possible association with large-scale circulation, J. Hydrol., 353, 215-227, 2008. 